\title{
Seleção de fornecedores no setor público: um estudo de caso em bio-manguinhos/ fiocruz
}

\section{Suppliers selection in the public setor: a case study in bio-manguinhos/fiocruz}

\author{
Deyves Mendes Paraguassu ${ }^{1}$ \\ Marcelo Alvaro da Silva Macedo²
}

\section{Resumo}

A Bio-Manguinhos atua no mercado de prevenção, diagnóstico e tratamento de doenças por meio de vacinas, reativos para diagnóstico e biofármacos. Por ser uma instituição pública, compartilha com o restante da máquina pública a dificuldade em obter recursos para investimento. Além disso, possui características peculiares, como o fato de que o desenvolvimento de seus produtos pode levar mais de 20 anos. Diante desse cenário, a busca por parcerias para minimizar o tempo de desenvolvimento de um produto e compartilhar os custos de investimento se mostra interessante. Nesse contexto, este trabalho tem por objetivo desenvolver uma ferramenta que auxilie Bio-Manguinhos a selecionar fornecedores que contribuirão para o desenvolvimento e a produção de novos produtos. Para tanto, foram realizadas duas etapas de entrevistas com a diretoria de Bio-Manguinhos: a primeira foi com os vice-diretores, na qual foram identificados os critérios relevantes para a seleção de fornecedores para novos produtos; a segunda etapa foi realizada com o diretor, na qual foram confirmados os critérios identificados pelos vice-diretores e utilizado um método de análise multicriterial, AHP - Análise Hierárquica, para atribuir pesos a esses critérios. Dessa forma, foi criada uma ferramenta com os critérios considerados relevantes e suas respectivas importâncias dentro desse ambiente, que busca auxiliar a organização a selecionar seus fornecedores para

Mestre em Gestão e Estratégia em Negócios - PPGEN/UFRuralRJ - Rod. BR 465, Km 07, PPGEN/ICHS/UFRRJ, Seropédica, RJ, 23.890-000 - (21) 26821042 - deyvesmendes@bio. fiocruz.br

2 Doutor em Engenharia de Produção - Mestrado em Ciências Contábeis da FACC/UFRJ - Av. Pasteur, 250, Depto de Contabilidade/FACC/UFRJ, Urca, Rio de Janeiro, RJ, 22.290-240 - (21) 38735119 - malvaro.facc.ufrj@gmail.com 
novos produtos. Os resultados mostram que os critérios relevantes e sua ordem são os seguintes: nível de desenvolvimento do produto, compatibilidade com o parque industrial, cumprimento de exigências regulatórias, rendimento do produto, solidez da empresa e custo. Isso mostra que critérios mais próximos à estratégia organizacional possuem uma importância maior.

Palavras-chave: Seleção de Fornecedores. Gestão Pública. AHP.

\section{Abstract}

Bio-Manguinhos works in the prevention, diagnosis and treatment of diseases through vaccines, diagnostic reagents and biopharmaceutical. Being a public institution, it shares with the rest of the public sector the difficulty in obtaining public funds for investment. Furthermore, it has characteristics such as the fact that the development of its products may take more than 20 years. Given this scenario, the search for partners to minimize development time of a product and share the cost of investment becomes interesting. In this context, this paper aims to develop a tool that helps BioManguinhos in selecting suppliers who contribute to the development and production of new products. For this, two stages of interviews were conducted with the BioManguinhos board: the first with the vice-directors, where were identified the relevant criteria for the suppliers selection for new products; the second stage was conducted with the director, where the criteria identified by the vice-directors were confirmed and was used a multicriteria analysis method, AHP - Analytic Hierarchy Process, to assign weights to these criteria. Thus, we created a tool, with the relevant criteria and their importance in this environment, seeking to help the organization to select suppliers for new products. The results show that the relevant criteria and their order are: level of product development, compatibility with the industrial park, compliance with regulatory requirements, product performance, company solvency and cost. This shows that the criteria closest to organizational strategy have a greater importance.

Keywords: Suppliers Selection. Public Mangement. AHP.

\section{Introdução}

Segundo Lima (2004), a tecnologia e sua complexidade estimulam as organizações a especializarem-se em determinados produtos, obrigando-as a comprar produtos de fornecedores especializados, detentores da propriedade intelectual e patentes associados à tecnologia ou ao produto. 
De acordo com Martins (2005), com o decorrer dos anos, a seleção de fornecedores vem ganhando cada vez mais importância. 0 aumento no valor dos itens comprados em relação ao total da receita das empresas, a aquisição de produtos de outros países, viabilizados pela globalização a preços competitivos, e a crescente velocidade na mudança de tecnologia, acompanhada por uma redução do ciclo de vida dos produtos, são alguns fatores que contribuem para o crescimento da seleção de fornecedores.

$\mathrm{Na}$ área pública, tem-se ainda que considerar aspectos particulares desse ambiente de gestão no que diz respeito à contratação de fornecedores. A Constituição Federal (CF/88) rege que a administração pública contrate obras, serviços, compras e alienações mediante processo de licitação pública que assegure igualdade de condições a todos os concorrentes (Art. 37, inciso XXI). A Lei Federal $n^{\circ}$ 8666/93, assim como as atualizações posteriores, regulamentam esse artigo da CF/88, instituindo normas para as licitações e os contratos. A Lei $n^{\circ} 10.520 / 2002$ institui, no âmbito da União, estados, Distrito Federal e municípios, a modalidade de licitação denominada de pregão para a aquisição de bens e serviços, e a Lei $n^{\circ}$ 11.079/2004 institui normas para licitação e contratação de parceria público-privada na administração pública.

Nesse contexto, o presente estudo faz uma análise do processo de seleção de fornecedores de uma instituição pública: a Bio-Manguinhos/ Fiocruz. A instituição foi criada com o objetivo de desenvolver e produzir produtos para prevenção, identificação e tratamento de doenças. Contudo, desenvolver um produto dessa magnitude pode levar, em diversos casos, mais de 20 anos, requerendo alto volume de recursos financeiros, recursos humanos capacitados e tecnologia disponível.

Diante desse cenário, a busca por parcerias externas tem se mostrado interessante, visto que o Brasil possui pouca capacidade de investimento em pesquisa e desenvolvimento de novos produtos e, consequentemente, de novas plataformas tecnológicas capazes de suportar a produção de novos produtos e atender à demanda da população do país. 
Aliada às restrições de investimento, ao alto custo dos medicamentos e à grande demanda, a escolha de fornecedores para a transferência de conhecimento, tecnologia e técnicas de produção se torna extremamente relevante.

Aliada ao baixo investimento em pesquisa e desenvolvimento do país, ao alto custo, ao tempo requerido para desenvolver um produto e às progressivas mudanças no ambiente de negócios, a gestão organizacional é continuamente desafiada.

Em virtude dessa maior complexidade e dinamismo, a BioManguinhos enfrenta situações muitas vezes incertas e busca, de maneira intensiva, meios para reagir e se adequar às constantes mudanças, com o objetivo de continuar a desenvolver e fabricar produtos para prevenção, identificação e tratamento de doenças.

Nessa perspectiva, uma das formas de acelerar o processo de desenvolvimento de novos produtos é ter fornecedores capazes de transferirem conhecimento e tecnologia suficientes para atender às necessidades da Bio-Manguinhos e do país.

No entanto, quando existe mais de um fornecedor para um mesmo produto, aspectos tecnológicos, custo do produto, investimento requerido, possibilidade de novos produtos, uso de tecnologia existente, grau de inovação, facilidade de aprendizado, entre outros aspectos, terão de ser avaliados para selecionar o fornecedor.

Em face de toda essa complexidade, tem-se o seguinte problema de pesquisa: como a Bio-Manguinhos selecionará seus fornecedores para auxiliarem na introdução de novos produtos?

Este artigo tem como objetivo desenvolver uma ferramenta, baseada em AHP, que auxilie Bio-Manguinhos a selecionar fornecedores que contribuirão para o desenvolvimento e produção de novos produtos. Isso é feito através de um instrumento que identifica e hierarquiza os critérios relevantes para a seleção de fornecedores, tendo como base as características estratégicas da instituição sob análise, que é voltada para pesquisa, desenvolvimento e inovação em produtos para o mercado de prevenção, diagnóstico e tratamento de doenças. 


\section{Seleção de fornecedores}

O principal objetivo da seleção de fornecedores é decidir sobre a mais apropriada fonte de fornecimento, e vem acompanhada de outras discussões importantes para a empresa, como a quantidade de fornecedores que participarão da carteira de abastecimento do item e o volume de pedidos a serem alocados para cada um desses fornecedores (WEBER; CURRENT, 1993).

A seleção de fornecedores impróprios às finalidades estratégicas das organizações pode ter como consequência a necessidade de uma futura substituição, o que implica em custos de mudança (AMARAL e DEMARI, 2006).

Aymard e Brito (2003 apud Furtado, 2005) detalharam alguns desses custos de mudança, relacionando-os em categorias como: recursos humanos (custos de treinamento, desgaste com o pessoal da empresa, gerenciamento da mudança); recursos físicos, econômicos e tecnológicos (custos de novos equipamentos, perdas de sinergia, estabelecimento de novos arranjos logísticos); percepção de risco (familiaridade de marca, confiança e economias de comunicação); garantias contratuais; e perdas de clientes.

Os processos de escolha de fornecedores são pertinentes a qualquer tipo de compra que a empresa deseja efetuar. Como as políticas de relacionamento com fornecedores variam em função da estratégia, há a necessidade de se desenvolverem métodos flexíveis de seleção de fornecedores que reflitam as estratégias corporativas, considerem as restrições de compradores e envolvam variáveis tangíveis e intangíveis (GHODSYPOUR; O'BRIEN, 1998 apud FURTADO, 2005).

A seleção de fornecedores é uma das etapas para a implantação da terceirização em uma empresa, já que selecionar o fornecedor correto em cada caso significa reduzir os riscos e os custos de transação, aumentando a competitividade da empresa. Para que a etapa de seleção de fornecedores seja eficaz, originando uma parceria de sucesso entre comprador e fornecedor, faz-se necessário determinar os critérios de 
seleção a serem considerados em cada processo (MOTWANI et al., 1999).

São os critérios de seleção que vão determinar quais pontos devem ser confrontados entre os fornecedores interessados na parceria ofertada. Embora exista uma diferença de critérios de seleção a serem considerados em cada atividade, é necessário que as empresas se baseiem em critérios corporativos, válidos para todas as atividades, de modo a criar uma identidade junto ao mercado de fornecedores e tornar claro suas prioridades e exigências (LIU, DING; LALL, 2000).

Para a seleção de fornecedores, existem critérios que têm deixado de ser somente aqueles básicos, ou seja, o preço pelo qual o fornecedor oferecia o produto, a qualidade do produto, que deveria atender à especificação mínima requerida pela empresa, e a velocidade de entrega do produto pelo fornecedor. O custo total de aquisição, que considera todos os custos associados à aquisição do produto; a qualidade total oferecida pelo fornecedor (não somente a qualidade mínima necessária); o serviço prestado pelo fornecedor, que, além da velocidade de entrega, passou a considerar a confiabilidade, o custo de transporte, a consistência e frequência de entregas; e a flexibilidade do fornecedor estão entre os novos critérios que passaram a ser adotados (GOFFIN et al., 1997 apud MARTINS, 2005).

Furtado (2005) e Faria e Vanalle (2006) acrescentam capacidade de desenvolvimento de novos produtos, capacidade tecnológica, performance econômica, compatibilidade gerencial e proximidade geográfica como critérios a serem avaliados na seleção de um fornecedor. Além desses atributos, Furtado (2005) inclui políticas de garantia, sentimento de confiança e serviços de pós-venda como critérios igualmente importantes. Já para Faria e Vanalle (2006), atendimento à legislação e aspectos relativos à segurança e ao meio-ambiente devem ser avaliados na seleção do fornecedor.

Segundo Slack, Chambers e Johnston (1999), a definição de com quantos e com quais fornecedores a empresa irá trabalhar faz parte da estratégia de compras. Aárea de compras deverá ponderar as vantagens 
e desvantagens de cada um dos modelos e selecionar o que melhor se adequar (ou os que melhor se adequarem) à estratégia e ao alcance da empresa. O tipo de relacionamento que a empresa pretende manter será também uma condição para a seleção dos fornecedores.

Kliem e Ludin (2000) enfatizam a importância de se desenvolver processos de seleção, os quais auxiliarão na avaliação e na decisão final da escolha dos fornecedores de serviços. Tais processos visam identificar fatores como: reputação, participação no mercado, responsabilidade, experiência, flexibilidade nos vários tipos de acordo possíveis, preço, tamanho e histórico de realizações.

Furtado (2005) complementa que existe a necessidade de desenvolvimento de métodos flexíveis para a seleção de fornecedores que reflitam a estratégia organizacional, considerem as restrições dos fornecedores e envolvam variáveis tangíveis e intangíveis.

Segundo Braga (2003), quando os objetivos de selecionar fornecedores estão alinhados à estratégia organizacional, vantagens como redução de custo, desenvolvimento de tecnologia e redução do tempo de introdução de um novo produto são obtidas.

Nesse sentido, Lambert, Emmelhainz e Gardner (1996) introduzem e definem o termo "parceria" como sendo um relacionamento de negócios que tem por objetivo aumentar a competitividade e o desempenho organizacional, com base em confiança mútua, compartilhamento de riscos e recompensas maiores dos que as alcançadas individualmente.

De acordo com Furtado (2005), a necessidade do desenvolvimento de competências em áreas diversas e a prazos cada vez menores leva as organizações a se unirem e a formarem alianças e parcerias de longo prazo.

Ainda de acordo com Kliem e Ludin (2000), ao desenvolverem os critérios de avaliação para seleção de fornecedores, os gerentes e executivos responsáveis pela equipe de avaliação devem observar os três aspectos seguintes: 1) criação de critérios específicos, 2) uso de critérios que minimizem vieses e mantenham objetividade e 3) obtenção de consenso dos membros da equipe de avaliação. 


\section{Metodologia}

Segundo Yin (2001), o estudo de caso é uma pesquisa empírica que investiga um determinado fenômeno dentro de seu contexto real. No entanto, ele deve considerar o desenvolvimento prévio de proposições teóricas para conduzir a coleta e análise de dados.

Murakami e Almeida (2003) acrescentam que o estudo de caso necessita de julgamentos sobre o que assistir e o seu significado. Nesse sentido, a capacidade, a interpretação e o julgamento do pesquisador são de extrema importância, bem como suas percepções sobre o significado do fenômeno pesquisado.

O estudo de caso está baseado em pesquisa em profundidade e, no presente artigo, foi executado por intermédio de entrevistas realizadas com os diretores e vice-diretores da Bio-Manguinhos, buscando identificar os pontos ou critérios importantes para a seleção de fornecedores, como custo, grau de tecnologia etc.

Segundo Oppenheim (apud Roesch, 1995), como a entrevista é um processo social, em que existe contato, deve-se levar em consideração a possibilidade de distorção das respostas em virtude de interpretações equivocadas. $O$ autor recomenda que o pesquisador se qualifique para reduzir, prevenir ou até evitar vieses na coleta dos dados. Antes de tudo, é essencial planejar as questões que serão abordadas e realizar um estudo piloto para verificar tanto o instrumento quanto a habilidade do pesquisador.

Para a coleta dos dados, foram desenvolvidos dois instrumentos. O primeiro possui o objetivo de identificar os critérios relevantes para a seleção de fornecedores para novos produtos, e o segundo instrumento, atribuir pesos a esses critérios por meio de uma comparação par a par entre os critérios encontrados no primeiro. Tanto o primeiro roteiro de entrevista, que foi aplicado aos vice-diretores, quanto o segundo, aplicado ao diretor, encontram-se nos anexos.

Para a análise do primeiro instrumento, utilizou-se a análise de frequência. Mattar (1998) ressalta que a escolha do método de análise 
dependerá do tipo de análise necessário e desejado. Quando se opta pelo método de análise descritiva, como a que foi feita na análise das respostas do primeiro roteiro de entrevista deste trabalho, pode-se utilizar a análise de frequência, que considera uma variável (pergunta) de cada vez. Segundo Malhotra (2001), a finalidade é conseguir uma contagem das respostas associadas a diferentes "valores" da variável.

Já para a análise dos resultados do segundo instrumento, foi utilizado um método de análise multicritério, denominado Analitic Hierarquic Process ou Análise Hierárquica (AHP), que se fundamenta na comparação de alternativas de escolhas, duas a duas, e na qual o decisor realiza pares de comparações relativas a duas alternativas da estrutura de decisão, questionando-se qual elemento satisfaz mais e quanto mais (ABREU; CAMPOS, 2007).

O AHP é um método de análise que considera e julga múltiplos atributos, baseando-se na ótica subjetiva e naturalmente inconsistente de seres humanos, e em dados concretos obtidos do mundo real através de medições inexatas (IAÑES; CUNHA, 2006).

Saaty (1990) argumenta que a grande vantagem do AHP é permitir aos seus usuários atribuir pesos relativos para múltiplos atributos, ou múltiplas alternativas para um dado atributo, ao mesmo tempo em que realiza uma comparação par a par entre eles.

Segundo Belderrain e Silva (2005), o método AHP, após a divisão do problema em níveis hierárquicos, determina, por meio da síntese dos valores dados pelos agentes de decisão, uma medida global para cada uma das alternativas, priorizando-as ou classificando-as ao final do método.

Ainda de acordo com os autores, logo após a construção da hierarquia, cada decisor deve fazer uma comparação, par a par, de cada elemento em um nível hierárquico dado, criando uma matriz de decisão quadrada. Nela, o decisor representará, a partir de uma escala definida, sua preferência entre os elementos comparados, sob o enfoque do nível imediatamente superior. A comparação par a par das alternativas é 
utilizada realizando uma escala linear própria, que varia de 1 a 9, a qual é denominada Escala Fundamental de Saaty (Quadro 01).

Quadro 1 - Escala de Saaty

\begin{tabular}{|c|c|}
\hline Pesos & Descrição \\
\hline 1 - Igual importância & $\begin{array}{l}\text { Duas atividades contribuem igualmente com } \\
\text { o objetivo. }\end{array}$ \\
\hline 3 - Importância moderada & $\begin{array}{l}\text { Experiência e julgamento favorecem } \\
\text { levemente uma atividade sobre a outra. }\end{array}$ \\
\hline 5 - Forte importância ou & Experiência e julgamento favorecem \\
\hline importância essencial & fortemente uma atividade sobre a outra. \\
\hline 7 - Importância demonstrada & $\begin{array}{l}\text { Uma atividade é fortemente favorecida e sua } \\
\text { dominância é demonstrada na prática. }\end{array}$ \\
\hline 9 - Importância absoluta & $\begin{array}{l}\text { A evidência que favorece uma das atividades } \\
\text { sobre a outra é clara e inquestionável. }\end{array}$ \\
\hline
\end{tabular}

Fonte: Adaptação Saaty (1990)

De maneira geral, Chan, Kwok e Duffy (2004) resumem os passos recomendados para a aplicação do AHP:

- Definir o problema e o que se procura saber; expor as suposições refletidas na definição do problema; identificar as partes envolvidas; checar como estas definem o problema e suas formas de participação no AHP.

- Decompor o problema desestruturado em hierarquias sistemáticas, do topo (objetivo geral) para o último nível (fatores mais específicos, usualmente as alternativas). Caminhando do topo para a extremidade, a estrutura do AHP contém objetivos, critérios (parâmetros de avaliação) e classificação de alternativas (medição da adequação da solução para o critério). Cada nó é dividido em níveis apropriados de detalhes. Quanto mais critérios, menos importante cada critério individual se torna, e a compensação é feita pela atribuição de pesos para 
cada um. É importante certificar-se de que os níveis estejam consistentes internamente e completos, e que as relações entre os níveis estejam claras.

- Construir uma matriz de comparação paritária entre os elementos do nível inferior e os do nível imediatamente acima. Em hierarquias simples, cada elemento de nível inferior afeta todos os elementos do nível superior. Em outras hierarquias, elementos de nível inferior afetam somente alguns elementos do nível superior, requerendo a construção de matrizes únicas.

- Fazer os julgamentos para completar as matrizes. Para isso, são necessários $n(n-1) / 2$ julgamentos para uma matriz $n \times$ $\mathrm{n}$, sendo $\mathrm{n}$ o número de linhas e colunas. $\mathrm{O}$ analista ou grupo participante julga se A domina o elemento B. Se afirmativo, inserir o número na célula da linha de $A$ com a coluna de $B$. A posição coluna $A$ com linha $B$ terá o valor recíproco. Assim prossegue-se o preenchimento da matriz.

- Testar a consistência e, se não for satisfatória, refazer julgamentos. Segundo Saaty (1991), o teste de consistência tem que ser de tal ordem que se possa testar não só a violação de transitividade (A é preferível a B; B é preferível a C; logo, A tem de ser preferível a $C$ ) como também a de proporcionalidade ( $A$ é duas vezes preferível a $B$; $B$ é três vezes preferível a $C$; logo, A tem de ser seis vezes preferível a C).

Essas etapas listadas da metodologia AHP são pormenorizadas por Gomes, Araya e Carignano (2004) da seguinte maneira: a primeira etapa é a de estruturação hierárquica do problema de decisão, na qual os decisores definem os critérios e a disposição deles em níveis hierárquicos necessários. Essa etapa visa construir uma representação do problema o mais consistente possível, tomando sempre como base a solução para o problema de decisão especificado. Determinam-se ainda nessa etapa as alternativas pertinentes a cada critério dispostas no nível hierárquico abaixo deste. 
A segunda etapa trata da modelagem, na qual são selecionados os critérios que irão apreender ao máximo a totalidade das preferências, com base no consenso entre os atores. Nessa fase, define-se como agregar performances de uma ação segundo os diversos critérios, de tal forma que a dita ação possa ser declarada boa ou ruim, melhor ou pior que a outra. Elegem-se ainda as informações concernentes à importância relativa dos critérios e como será feita tal eleição. Nessa etapa, utiliza-se o método propriamente dito.

Deve-se ter o cuidado para não criar um modelo que leve a uma irrealidade, pois, do contrário, será obtida uma solução sem nenhum resultado prático. Para essa fase, pode-se utilizar como ferramenta de apoio a matriz de desempenho ou a tabela de consequência, na qual cada linha descreve uma opção/alternativa e cada coluna descreve o desempenho das opções em função de cada critério, a fim de comparar cada opção em relação aos diferentes critérios (GOMES; ARAYA ; CARIGNANO, 2004).

Para a construção da matriz de desempenho, são necessárias algumas análises, como a análise de dominância, que objetiva verificar se algumas opções são dominadas por outras por meio da comparação de cada opção em relação a cada critério. A opção pode ser considerada dominante quando ela tem desempenho pelo menos tão bom quanto a outra em todos os critérios ou é estritamente melhor que a outra em pelo menos um critério.

A outra análise que os intervenientes devem fazer é se há compensações (trade-offs) entre os critérios e, em caso positivo, analisar se os trade-offs são aceitáveis. Assim, o bom desempenho de um critério pode, em princípio, compensar o desempenho mais fraco de outro. Com relação à fase de avaliação, pode-se dizer que ela consiste em esclarecer os intervenientes acerca das escolhas, através da aplicação de métodos e metodologias muticritérios para apoiar a análise e a mensuração das preferências, ou seja, sinalizar ao decisor acerca da mensuração das ações propostas no modelo, segundo os diversos pontos de vista. Para essa fase, existem algumas técnicas disponíveis 
nas quais a compensação é aceitável, mas o que as diferenciam é a forma como são atribuídos os valores (GOMES, ARAYA; CARIGNANO, 2004).

De acordo com Saaty (1990), a metodologia deve ser útil para formular problemas incorporando conhecimentos e julgamentos, de forma que as questões envolvidas sejam claramente articuladas, avaliadas, debatidas e priorizadas. Os julgamentos podem ser apurados através da contínua aplicação de um processo de realimentação, em que cada aplicação tende a aprimorar as análises, com a meta de obter as melhores escolhas para a solução do problema.

Segundo Saaty (1990), o benefício do método é que, como os valores dos julgamentos das comparações paritárias são baseados em experiência, intuição e dados físicos, o AHP pode lidar com aspectos qualitativos e quantitativos de um problema de decisão. Contudo, é preciso reconhecer as limitações do método. Uma delas é a sua aplicação inadequada, isto é, em ambientes desfavoráveis, onde a aplicação é percebida como simplificação excessiva ou desperdício de tempo (GRANDZOL, 2005).

\section{Apresentação do caso}

Quando de sua criação, em 4 de maio de 1976, a Bio-Manguinhos herdou as instalações de produção das vacinas existentes na Fiocruz. Ainda nesse ano, por intermédio de um instituto francês, obteve a tecnologia para produção da vacina contra a meningite meningocócica para os sorotipos A e C, de acordo com a necessidade da época.

A mesma estratégia foi usada na década de 1980, quando foi transferida de uma universidade japonesa para a Bio-Manguinhos a tecnologia para a produção da vacina contra o sarampo e a poliomielite.

De acordo com Leal (2004), esses processos de transferência de tecnologia possibilitaram que a Bio-Manguinhos criasse competências indispensáveis ao processo de desenvolvimento de uma nova vacina. 
Após um período de crescimento, entre o final da década de 1980 e o início da década de 1990, que permitiu a projeção de uma imagem nacional e internacional de uma instituição capaz de grandes realizações, a Bio-Manguinhos passou a enfrentar grandes dificuldades de ordem econômica, financeira e gerencial, explicada pela estrutura rígida e limitada de administração que levou a instituição a permanecer em uma posição muito aquém de suas expectativas e potencial.

Esse contexto levou à falta de motivação, à redução do quadro de pessoal e à obsolescência do parque industrial. A lógica de distribuição do orçamento da Fiocruz não considerava as necessidades de uma unidade fabril, onde os recursos destinados eram insuficientes e não permitiam a manutenção adequada das instalações e dos equipamentos.

Por maiores que tenham sido os esforços na tentativa de recompor o quadro de pessoal e estabelecer um planejamento estratégico, a crise atinge seu auge em 1996.

Diante desse cenário, um grupo formado por profissionais da BioManguinhos e da Fiocruz elaboraram uma proposta de um novo modelo de gestão para a Bio-Manguinhos, diferenciado do restante da Fiocruz, tendo como base o estabelecimento de contratos de gestão para a busca da autossustentabilidade, em que o instituto teria seu orçamento formado a partir dos produtos vendidos ao governo brasileiro e da exportação do excedente de produção. Esse modelo foi aprovado e implantado em 1997 (GADELHA, 1997; FIOCRUZ, 1997).

A base filosófica desse modelo foi que as atividades produtivas seriam geridas e sustentadas com os resultados do instituto. Desde então, a Bio-Manguinhos funciona assim. A criação desse modelo gerou um ganho significativo para os demais institutos da Fiocruz, pois a parcela destinada à Bio-Manguinhos foi distribuída entre esses institutos.

Após a adoção do novo modelo de gestão, a Bio-Manguinhos buscou a ampliação de sua carteira de produtos, com vacinas mais modernas e maior valor agregado, garantindo sua sustentabilidade e a 
possibilidade de investimentos em pesquisa e desenvolvimento interno (LEAL, 2004).

Essa busca se deu, principalmente, por intermédio de acordos de transferência de tecnologia. Esses processos de transferência de tecnologia de vacinas mais modernas e com maior valor agregado demonstram, mais uma vez, a capacidade técnica do instituto, pois, segundo Gadelha (1990), os processos de transferência de tecnologia constituem uma importante ferramenta para diminuir a defasagem tecnológica entre instituições e uma aposta com alto risco inerente. Se não houver esforço para a absorção e implantação da tecnologia, existe a possibilidade de que a fronteira do conhecimento já tenha se deslocado, retornando à situação de dependência.

Para Guimarães et al. (1985), a transferência de tecnologia pode ser um importante instrumento para o aprendizado, desde que articulado com algum grau de investimento em pesquisa e desenvolvimento interno. Não é a importação de tecnologia que caracteriza a dependência, e sim o não aprendizado interno. Dessa forma, é preciso avaliar se a instituição está preparada para receber determinada tecnologia. Optar por transferência de tecnologia é optar por algo que foi desenvolvido e testado por alguém. Dessa forma, a possibilidade de sucesso é maior.

Para sustentar esse crescimento, a estrutura de Bio-Manguinhos está divida da seguinte forma:

Figura 1 - Estrutura de Bio-Manguinhos

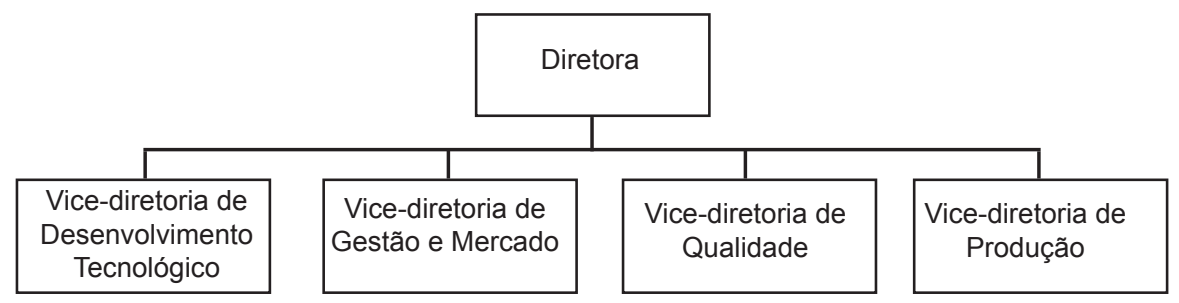

Fonte: Bio-Manguinhos (2008). 
Cabe a cada vice-diretor apoiar o diretor na tomada de decisão, cada qual dentro de sua especialidade. Dessa forma, a coleta de dados será com os vice-diretores e com o diretor.

Atualmente, a Bio-Manguinhos conta com uma carteira de 29 produtos disponíveis para venda e 33 projetos para desenvolvimento de novos produtos. Como missão, busca contribuir para a melhoria dos padrões da saúde pública brasileira através da pesquisa e produção de imunobiológicos para atender às demandas geradas pelo quadro epidemiológico nacional e mundial (BIO-MANGUINHOS, 2008). Sua visão é fazer parte da base tecnológica do Estado brasileiro para apoiar as políticas públicas, ofertando produtos de interesse epidemiológico e sanitário por meio de parcerias, pesquisa e desenvolvimento (BIOMANGUINHOS, 2008).

\section{Análise dos resultados}

$\mathrm{Na}$ busca pelos critérios mais relevantes para a seleção de um determinado fornecedor para novos produtos, a coleta de dados foi dividida em três etapas: a primeira busca quais os critérios relevantes para a seleção de um fornecedor, a segunda busca selecionar os cinco critérios mais relevantes e a terceira busca uma hierarquização entre eles, ou seja, o grau de importância entre os cinco critérios, do mais ao menos importante.

O vice-diretor de desenvolvimento tecnológico elencou sete critérios relevantes para a seleção de um fornecedor: compatibilidade com o parque industrial, competência em transferência de tecnologia, cumprimento de exigências regulatórias, custo, nível de desenvolvimento do produto, rapidez no desenvolvimento de melhorias e solidez da empresa. Ele descartou "compatibilidade com o parque industrial" e "rapidez no desenvolvimento de melhorias" para reduzir a cinco os critérios mais relevantes. Como grau de importância, do maior para o menor, considerou: nível de desenvolvimento do produto, cumprimento 
de exigências regulatórias, custo, competência em transferência de tecnologia e solidez da empresa.

A vice-diretora de qualidade elencou seis critérios: compatibilidade com o parque industrial, cumprimento de exigências regulatórias, custo, nível de desenvolvimento do produto, porte do fornecedor e solidez da empresa. Ela descartou "porte do fornecedor" para reduzir a cinco os critérios mais relevantes. Como grau de importância, do maior para o menor, considerou: nível de desenvolvimento do produto, compatibilidade com o parque industrial, cumprimento de exigências regulatórias, custo e solidez da empresa.

O vice-diretor de produção elencou cinco critérios: cumprimento de exigências regulatórias, custo, nível de desenvolvimento do produto, registro do produto no país de origem e uso da plataforma em outros produtos. Como não houve a necessidade de redução da quantidade de critérios, como grau de importância, do maior para o menor, considerou: nível de desenvolvimento do produto, custo, uso da plataforma em outros produtos, cumprimento de exigências regulatórias e registro do produto no país de origem.

A vice-diretora de gestão e mercado elencou seis critérios: compatibilidade com o parque industrial, custo, histórico de parcerias, nível de desenvolvimento do produto, rendimento do produto e solidez da empresa. Ela descartou "compatibilidade com o parque industrial" para reduzir a cinco os critérios mais relevantes. Como grau de importância, do maior para o menor, considerou: nível de desenvolvimento do produto, rendimento do produto, custo, histórico de parcerias e solidez da empresa.

Baseado nos critérios apontados como os cinco mais importantes pelos respondentes, foram elencados 10 critérios distintos, conforme Quadro 02. 
Quadro 2 - 10 critérios para seleção de fornecedores

\section{Critérios}

Compatibilidade com o parque industrial

Competência em transferência de tecnologia

Cumprimento de exigências regulatórias

Custo

Histórico de parcerias

Nível de desenvolvimento do produto

Registro do produto no país de origem

Rendimento do produto

Solidez da empresa

Uso da plataforma em outros produtos

Para reduzir essa quantidade para cinco critérios - objetivo dessa coleta de dados -, foram realizadas três análises: 1) análise de frequência simples, considerando o critério, independentemente da hierarquia apontada pelos respondentes; 2) frequência com que os critérios aparecem em primeiro; e 3) frequência com que os critérios aparecem em segundo lugar. A Tabela 01 mostra os resultados dessas análises.

Tabela 1 - Analise de frequência dos 10 critérios para seleção de fornecedores

\begin{tabular}{l|c|c|c}
\hline \multicolumn{1}{c|}{ Critérios } & $\begin{array}{c}\text { Frequência } \\
\text { simples }\end{array}$ & $\begin{array}{c}\text { Frequência } \\
\text { como 10 } \\
\text { critério }\end{array}$ & $\begin{array}{c}\text { Frequência } \\
\text { como 2 } \\
\text { critério }\end{array}$ \\
\hline $\begin{array}{l}\text { Compatibilidade com o parque } \\
\text { industrial }\end{array}$ & 1 & 0 & 1 \\
\hline $\begin{array}{l}\text { Competência em transferência de } \\
\text { tecnologia }\end{array}$ & 1 & 0 & 0 \\
\hline $\begin{array}{l}\text { Cumprimento de exigências } \\
\text { regulatórias }\end{array}$ & 3 & 0 & 1 \\
\hline Custo & 4 & 0 & 1 \\
\hline Histórico de parcerias & 1 & 0 & 0 \\
\hline Nível de desenvolvimento do produto & 4 & 4 & 0 \\
\hline Registro do produto no país de origem & 1 & 0 & 0 \\
\hline Rendimento do produto & 1 & 0 & 1 \\
\hline Solidez da empresa & 3 & 0 & 0 \\
\hline Uso da plataforma em outros produtos & 1 & 0 & 0 \\
\hline
\end{tabular}


Ao consolidar os critérios apontados por cada análise de frequência, obtém-se o nível de desenvolvimento do produto, custo, cumprimento de exigências regulatórias, solidez da empresa, compatibilidade com o parque industrial e rendimento do produto como os critérios mais relevantes para a seleção de um fornecedor, conforme aponta o Quadro 03.

Quadro 3 - Seleção dos 6 critérios mais relevantes para a seleção de fornecedores

\begin{tabular}{|l|}
\hline Frequencia total \\
\hline Nível de desenvolvimento do produto \\
\hline Custo \\
\hline $\begin{array}{l}\text { Cumprimento de exigências } \\
\text { regulatórias }\end{array}$ \\
\hline Solidez da empresa \\
\hline Frequência como $\mathbf{1}^{\circ}$ critério \\
\hline Nível de desenvolvimento do produto \\
\hline Frequência como $\mathbf{2}^{\circ}$ critério \\
\hline $\begin{array}{l}\text { Compatibilidade com o parque } \\
\text { industrial }\end{array}$ \\
\hline $\begin{array}{l}\text { Cumprimento de exigências } \\
\text { regulatórias }\end{array}$ \\
\hline Custo \\
\hline Rendimento do produto \\
\hline
\end{tabular}

\begin{tabular}{|l|}
\hline Critérios \\
\hline $\begin{array}{l}\text { Nível de desenvolvimento do } \\
\text { produto }\end{array}$ \\
\hline Custo \\
\hline $\begin{array}{l}\text { Cumprimento de exigências } \\
\text { regulatórias }\end{array}$ \\
\hline Solidez da empresa \\
\hline $\begin{array}{l}\text { Compatibilidade com o parque } \\
\text { industrial }\end{array}$ \\
\hline Rendimento do produto \\
\hline
\end{tabular}

Note-se que foram evidenciados seis critérios em função das análises de frequências, e não cinco, como esperado inicialmente. Por conta disso, serão utilizados esses seis critérios para a etapa junto ao diretor.

Segundo os respondentes, o critério "nível de desenvolvimento do produto" é relacionado ao nível de desenvolvimento tecnológico tanto do produto quanto da plataforma de produção. Ao selecionar um fornecedor que detenha um produto com maior grau de desenvolvimento, espera-se aprender a partir de uma tecnologia mais moderna. 
O critério "custo" não é apenas o custo de aquisição, mas todos os custos envolvidos: custos de compra, transporte, processamento, implantação, treinamento etc.

O critério "cumprimento de exigências regulatórias" está relacionado com o atendimento das normas regulatórias brasileiras ou de países com normas semelhantes.

Quanto ao critério "solidez da empresa", como as parcerias são de longo prazo, superiores a 15 anos, é importante que a empresa mantenha os objetivos da parceria firmada e, principalmente, sobreviva durante esse período.

O critério "compatibilidade com o parque industrial" está relacionado com a utilização do parque industrial atual. Apesar de se buscar novas tecnologias, buscam-se tecnologias que possam ser incorporadas no parque industrial, e não tecnologias que sugiram descartar o parque industrial atual para a criação de outro.

Quanto ao critério "rendimento do produto", como a empresa trabalha com produtos biológicos, organismos vivos, o rendimento é afetado diretamente pelo processo de produção adotado, e não necessariamente pelo tamanho dos equipamentos. Dessa forma, não adianta possuir grandes equipamentos se o processo não reproduzir condições ideais para o crescimento e a reprodução desses organismos.

De acordo com a literatura utilizada para este trabalho, os critérios elencados pelos vice-diretores, em sua essência, não são novos, portanto, já mencionados por outros pesquisadores. As variáveis existem, no entanto, cabe a cada organização selecionar um conjunto delas que auxilie na tomada de decisão.

Com base nas variáveis, foi solicitado que o diretor fizesse comparações par a par, atribuindo relações entre esses critérios de acordo com a escala de nove níveis de Saaty.

Antes de realizar as comparações par a par dos critérios, o diretor confirmou que os critérios identificados pelos vices são realmente importantes para a seleção de um fornecedor para novo produto. 
Conforme orientação para a comparação par a par, foi respondido primeiro qual o critério mais importante e, depois, atribuído peso, conforme a escala de Saaty. Os dados são demonstrados na Tabela 02.

Tabela 2 - Resultado para comparação par a par

\begin{tabular}{|c|c|c|c|c|}
\hline \multicolumn{3}{|l|}{ Critérios } & \multirow{2}{*}{$\begin{array}{l}\text { Critério mais } \\
\text { importante } \\
\text { (Coluna ?) }\end{array}$} & \multirow[b]{2}{*}{ Escala } \\
\hline Coluna 1 & & Coluna 2 & & \\
\hline \multirow{5}{*}{$\begin{array}{l}\text { Nível de } \\
\text { desenvolvimento } \\
\text { do produto }\end{array}$} & $x$ & Custo & 1 & 9 \\
\hline & $x$ & $\begin{array}{l}\text { Cumprimento de } \\
\text { exigências regulatórias }\end{array}$ & 1 & 4 \\
\hline & $x$ & Solidez da empresa & 1 & 6 \\
\hline & $x$ & $\begin{array}{l}\text { Compatibilidade com o } \\
\text { parque industrial }\end{array}$ & 1 & 3 \\
\hline & $x$ & Rendimento do produto & 1 & 5 \\
\hline \multirow{4}{*}{ Custo } & $x$ & $\begin{array}{l}\text { Cumprimento de } \\
\text { exigências regulatórias }\end{array}$ & 2 & 5 \\
\hline & $x$ & Solidez da empresa & & 2 \\
\hline & $x$ & parque industrial & 2 & 6 \\
\hline & $x$ & Rendimento do produto & 2 & 4 \\
\hline \multirow{3}{*}{$\begin{array}{l}\text { Cumprimento } \\
\text { de exigências } \\
\text { regulatórias }\end{array}$} & $x$ & Solidez da empresa & 1 & 4 \\
\hline & $x$ & $\begin{array}{l}\text { parque industrial } \\
\text { patiblidade com o }\end{array}$ & 2 & 3 \\
\hline & $x$ & Rendimento do produto & 1 & 3 \\
\hline \multirow{2}{*}{$\begin{array}{l}\text { Solidez da } \\
\text { empresa }\end{array}$} & $x$ & $\begin{array}{l}\text { Compatibilidade com o } \\
\text { parque industrial }\end{array}$ & 2 & 5 \\
\hline & $x$ & Rendimento do produto & 2 & 3 \\
\hline $\begin{array}{l}\text { Compatibilidade } \\
\text { com o parque } \\
\text { industrial }\end{array}$ & $x$ & Rendimento do produto & 1 & 4 \\
\hline
\end{tabular}


De acordo com a metodologia AHP, os dados foram transcritos em uma matriz $6 \times 6$, sendo preenchidas as relações contrárias correspondentes, ou seja, quando foi respondido que o critério 1 é mais importante que o 2 e atribuído peso de 3 , a relação contrária correspondente é $1 / 3$, ou seja, o critério 2 em relação ao 1. A Tabela 03 mostra esses resultados.

Cabe ressaltar que, a partir dos resultados da Tabela 03, foi realizada a análise de consistência considerando o Índice Randon (IR) de 1,24 , valor referente para seis variáveis, e o resultado obtido foi dentro do limite aceitável (a razão de consistência obtida foi de 0,059, sendo menor que 0,10 considerado como valor limite para consistência), demonstrando que o julgamento foi coerente em seu conjunto.

Após a aplicação da metodologia AHP, foram obtidos a hierarquia entre os critérios e o grau de importância de cada critério, refletindo não só o que a Bio-Manguinhos considera importante para a seleção de um determinado fornecedor, mas também gerando uma ferramenta de análise para a tomada de decisão que poderá ser utilizada na análise e seleção de fornecedores em futuras parcerias de desenvolvimento de novos produtos. Os pesos e os critérios são demonstrados a seguir (Tabela 04).

Tabela 3 - Matriz $6 \times 6$ para a AHP

\begin{tabular}{l|c|c|c|c|c|c}
\hline & $\begin{array}{c}\text { Nível de } \\
\text { desenvolvi- } \\
\text { mento do } \\
\text { produto }\end{array}$ & Custo & $\begin{array}{c}\text { Cumpri- } \\
\text { mento de } \\
\text { exigências } \\
\text { regulatórias }\end{array}$ & $\begin{array}{c}\text { Solidez } \\
\text { da } \\
\text { empresa }\end{array}$ & $\begin{array}{c}\text { Compatibili- } \\
\text { dade com } \\
\text { o parque } \\
\text { industrial }\end{array}$ & $\begin{array}{c}\text { Rendimento } \\
\text { do produto }\end{array}$ \\
\hline $\begin{array}{l}\text { Nível de } \\
\text { desenvolvimento } \\
\text { do produto }\end{array}$ & 1 & 9 & 4 & 6 & 3 & 5 \\
\hline Custo & $1 / 9$ & 1 & $1 / 5$ & $1 / 2$ & $1 / 6$ & $1 / 4$ \\
\hline $\begin{array}{l}\text { Cumprimento } \\
\text { de exigências } \\
\text { regulatórias }\end{array}$ & $1 / 4$ & 5 & 1 & 4 & $1 / 3$ & 3 \\
\hline $\begin{array}{l}\text { Solidez da } \\
\text { empresa }\end{array}$ & $1 / 6$ & 2 & $1 / 4$ & 1 & $1 / 5$ & $1 / 3$ \\
\hline $\begin{array}{l}\text { Compatibilidade } \\
\text { com o parque } \\
\text { industrial }\end{array}$ & $1 / 3$ & 6 & 3 & 5 & 1 & 4 \\
\hline $\begin{array}{l}\text { Rendimento do } \\
\text { produto }\end{array}$ & $1 / 5$ & 4 & $1 / 3$ & 3 & $1 / 4$ & 1 \\
\hline
\end{tabular}


Como observado, a importância de cada critério é bem distinta. Alguns possuem um grande peso nesse processo decisório de escolha de parceiros e outros são menos relevantes. O critério mais relevante (nível de desenvolvimento do produto) representa quase a metade da importância total. Ao somar os pesos dos outros três critérios mais relevantes (compatibilidade com o parque industrial, cumprimento de exigências regulatórias e rendimento do produto), obtém-se uma representatividade de mais de $90 \%$ do total.

Dessa forma, as empresas que desejarem fornecer à Bio-Manguinhos devem possuir bom desempenho nesses quatro primeiros critérios, visto que são os mais importantes.

Tabela 4 - Pesos dos critérios para seleção de fornecedor de novos produtos

\begin{tabular}{l|c|c}
\hline Critério & Peso & Hierarquia \\
\hline Nível de desenvolvimento do produto & 0,42596 & 1 \\
\hline Compatibilidade com o parque industrial & 0,24640 & 2 \\
\hline Cumprimento de exigências regulatórias & 0,15228 & 3 \\
\hline Rendimento do produto & 0,09352 & 4 \\
\hline Solidez da empresa & 0,04994 & 5 \\
\hline Custo & 0,03191 & 6 \\
\hline Total & 1,00000 & \\
\hline
\end{tabular}

Os critérios identificados vão de encontro com Braga (2003), Resende, Mendonça e Araújo (2005) e Pereira, Tontini e Silveira (2004), quando afirmam que a seleção de fornecedores deixa de avaliar apenas custos para se tornar uma área que apoia a estratégia da organização.

Conforme a hierarquia e os pesos dos critérios considerados relevantes pela Bio-Manguinhos, critérios mais próximos da estratégia organizacional possuem uma representatividade maior que critérios como "custos". Esse é o caso de critérios como o nível de desenvolvimento que o produto possui, a compatibilidade com o parque industrial e o atendimento a exigências regulatórias.

Ao considerar o critério "solidez da empresa", a Bio-Manguinhos busca se resguardar de futuras substituições prematuras de um 
fornecedor, dificultando a implantação da estratégia determinada - fato esse relacionado com Amaral e Demari (2006), quando dizem que a seleção de fornecedores impróprios às finalidades estratégicas da organização gerará a necessidade de substituição desse fornecedor.

\section{Considerações finais}

O aumento do portfólio de produtos e o aumento de suas vendas são os objetos de busca de muitas organizações. No entanto, para que a organização consiga cumprir esse papel, é necessário que ela possua produtos capazes de atender às necessidades de seus clientes.

Com o aumento do acesso a informações, tecnologias e mercados, as opções de fornecimento são ampliadas, tornando necessária a seleção de um fornecedor que melhor contribua para o sucesso organizacional. Porém, esse processo de seleção de fornecedores, quando em desacordo com as finalidades estratégicas das organizações, pode ter como consequência a necessidade de uma futura substituição, o que implica custos de mudança. Nesse sentido, selecionar o fornecedor certo pode significar a diferença entre o sucesso e o insucesso.

A Bio-Manguinhos, nos últimos anos, vivenciou esse cenário, com o aumento do portfólio e das vendas, e necessita desenvolver novos produtos continuamente. Porém, o mercado no qual atua é um mercado em que o tempo necessário ao desenvolvimento de um produto é, em muitos casos, superior a 20 anos, requerendo grande volume de investimento, não somente financeiros, mas em áreas físicas com tecnologia necessária, recursos humanos capacitados, rede de fornecimento capaz de ofertar produtos de boa qualidade etc.

Visando amenizar os problemas com a sua sustentabilidade financeira, a Bio-Manguinhos elaborou um mecanismo diferenciado de relacionamento com o governo brasileiro, que é seu principal cliente, pois sua receita é formada com base na comercialização de seus produtos, e não mais dependendo apenas de repasse deste governo. 
Apesar desse novo modelo de relacionamento com o governo, a Bio-Manguinhos ainda compartilha com o restante da máquina pública dificuldades em investir no volume necessário ao seu crescimento desejado.

Associando 0 fato do elevado tempo necessário ao desenvolvimento de um produto com a capacidade restrita de financiamento, a Bio-Manguinhos busca parceiros capazes de minimizar essa dificuldade. Baseado nesse contexto, a presente pesquisa teve o objetivo de identificar quais são os critérios relevantes para selecionar um determinado fornecedor em detrimento de outros.

A Bio-Manguinhos elegeu nível de desenvolvimento do produto, compatibilidade com o parque industrial, cumprimento de exigências regulatórias, rendimento do produto, solidez da empresa e custo como seus critérios relevantes para comparar os fornecedores e selecionar apenas um, possuindo cada critério mencionado um peso diferenciado.

Desses seis critérios, o nível de desenvolvimento do produto responde por mais de $42 \%$ do grau de importância dos critérios para escolha do fornecedor. Além disso, esse critério, junto com compatibilidade com o parque industrial, cumprimento de exigências regulatórias e rendimento do produto, que são critérios muito próximos à estratégia da organização, respondem por cerca de $90 \%$ do grau de importância total.

Os critérios identificados pela Bio-Manguinhos, em sua essência, não são novos; são critérios conhecidos e mencionados por outros pesquisadores. No entanto, como em toda tomada de decisão, especialmente as multicriteriais, cada organização busca identificar as variáveis importantes para uma determinada tomada de decisão, e essa escolha não necessariamente é a melhor para outras organizações. Além de cada organização identificar suas variáveis ou critérios relevantes para determinada tomada de decisão, o grau de importância que atribui a cada critério ou variável pode também diferenciar entre as organizações.

Como não foi objeto deste estudo testar os resultados obtidos, ou seja, os critérios relevantes com seus respectivos pesos, sugerimos 
que trabalhos futuros verifiquem se os resultados de decisões tomadas no passado seriam os mesmos ao utilizarem os pesos e critérios identificados neste trabalho como base para a tomada de decisão.

\section{Referências}

AAKER, D. A.; KUMAR, V.; DAY, G. S. Pesquisa de marketing. 2. ed. São Paulo: Atlas, 2004.

ABREU, A.. O.; CAMPOS, R. O método AHP/ABC aplicado em uma indústria de serviços. In: ENCONTRO NACIONAL DE ENGENHARIA DE PRODUÇÃO, 27., 2007, Foz do Iguaçu. Anais... Foz do Iguaçu, 2007. 1 CD-ROM.

AMARAL, D. S. do; DEMARI, E. C. Classificação e avaliação do desempenho dos fornecedores dos itens $A$ da curva $A B C$ do programa de medicamentos excepcionais pelo método de análise de gastos do ICHC - FMUSP. 2006. 45 f. Trabalho de Conclusão de Curso (Especialização)-Universidade de Brasília, DF, 2006.

BELDERRAIN, M. C. N.; SILVA, R. M. Considerações sobre métodos de decisão multicritério. In: ENCONTRO DE INICIAÇÃO CIENTÍFICA E PÓS GRADUAÇÃO DO ITA, 11., 2005, São José dos Campos. Anais... São José dos Campos, 2005. v. 1. p. 1-7.

BIO-MANGUINHOS. Relatório de atividades 2008: gestão, produção, qualidade e inovação. Rio de Janeiro, 2008.

BRAGA, A. Evolução estratégica do processo de compras ou suprimentos de bens e serviços nas empresas. Rio de Janeiro: Instituto Coppead, 2003.

BRASIL. Lei $n^{\circ}$ 8.666, de 21 de junho de 1993. Regulamenta o art. 37, inciso XXI, da Constituição Federal, institui normas para licitações e contratos da Administração Pública. Disponível em: <http://www. planalto.gov.br/ccivil_03/LEIS/L8666cons.htm>. Acesso em: 30 abr. 2010. 
. Lei $n^{\circ} 11.079$ de 30 de dezembro de 2004. Institui normas gerais para licitação e contratação de parcerias público-privada no âmbito da administração pública. Disponível em: <http://www.planalto. gov.br/ccivil_03/_Ato2004-2006/2004/Lei/L11079.htm>. Acesso em: 30 abr. 2010.

CHAN, A. H. S.; KWOK, W. Y.; DUFFY, V. G. Using AHP for determining priority in a safety management system. Industrial Management \& Data Systems, Bradford, v. 104, n. 5, p. 430-445, 2004.

FARIA, P. O.; VANALLE, R. M. Critérios para seleção de fornecedores: uma análise das práticas de grandes empresas industriais do estado do Espírito Santo. In: ENCONTRO NACIONAL DE ENGENHARIA DE PRODUÇÃO, 26., 2006, Fortaleza. Anais... Fortaleza, 2006. 1 CDROM.

FURTADO, G. A. P. Critérios de seleção de fornecedores para relacionamentos de parceria: um estudo em empresas de grande porte. 2005. 131 f. Dissertação (Mestrado em Administração)Universidade de São Paulo, 2005.

GADELHA, C. A. G. Biotecnologia em saúde: um estudo da mudança tecnológica na indústria farmacêutica e das perspectivas de seu desenvolvimento no Brasil. 1990. 356 f. Dissertação (Mestrado em Economia)-Universidade de Campinas, Campinas, SP, 1990.

GADELHA, C. A. G. Reforma, fortalecimento e legetimidade social: proposta de um novo modelo de gestão para Bio-Manguinhos. Rio de Janeiro: Fiocruz, 1997.

GOMES, L. A. M.; ARAYA, M. C. G.; CARIGNANO, C. Tomada de decisões em cenários complexos. São Paulo: Pioneira Thomson Learning, 2004.

GRANDZOL, J. R. Improving the faculty Selection process in higher education: a case for the analytic hierarchy process. IR Applications, Tallahassee, v. 6, n. 24, 2005. 
GUIMARÃES, E. A.; ARAUJO, J. T.; ERBER, F. A política científica e tecnológica: Brasil os anos de autoritarismo. Rio de Janeiro: Zahar, 1985.

IAÑES, M. M.; CUNHA, C. B. Uma metodologia para a seleção de um provedor logístico. Revista Produção, São Paulo, v. 16, n. 3, p. 394412, 2006.

KLIEM, R. L.; LUDIN, I. S. The essentials for successful it outsourcing. In: TINNIRELLO, P. C. New directions in Project Management. New York: Auerbach Publication, 2000. cap. 25, p. 281-289.

LAMBERT, D.; EMMELHAINZ, M. A; GARDNER, J. T. Developing and implementing supply chain partnerships. The International Journal of Logistics Management, Bradford, v. 7, n. 2, p. 1-17, 1996.

LEAL, M. L. F. Desenvolvimento tecnológico de vacinas em BioManguinhos/Fiocruz: uma proposta de gestão. 2004. $148 \mathrm{f}$. Dissertação (Mestrado Profissional em Gestão de C\&T em Saúde)Escola Nacional de Saúde Pública, Fundação Oswaldo Cruz, Rio de Janeiro, 2004.

LIMA, J. C. de S. Um estudo sobre a reconfiguração da função compras em empresas do setor automotivo. 2004. 172 f. Tese (Doutorado em Engenharia de Produção)-Departamento de Engenharia de Produção, Escola Politécnica da Universidade de São Paulo, São Paulo, 2004.

LIU, J.; DING, F. Y.; LALL, V. Using data envelopment analysis to compare suppliers for supplier selection and performance improvement. Supply Chain Management: An International Journal, Bradford, v. 5, n. 3, p. 143-15, 2000.

MALHOTRA, N. K. Pesquisa de marketing: uma orientação aplicada. 3. ed. Porto Alegre: Bookman, 2001.

MARTINS, R. Estratégia de compras na indústria brasileira de higiene pessoal e cosméticos: um estudo de casos. 2005. 124 f. Dissertação 
(Mestrado em Administração)-Instituto COPPEAD, Universidade Federal do Rio de Janeiro, Rio de Janeiro, 2005.

MATTAR, F. N. Pesquisa de marketing. 2. ed. São Paulo: Atlas, 1998. v. 2.

MOTWANI, J. et al. Supplier selection in developing countries: a model development. Integrated Manufacturing Systems, Bradford, v. 10, n. 3, p. 154-162, 1999.

MURAKAMI, M.; ALMEIDA, M. Decisão estratégica em TI: um estudo de caso. 2003. 154 f. (Dissertação de Mestrado)-Faculdade de Economia, Administração e Contabilidade da Universidade de São Paulo, 2003.

PEREIRA, R.; TONTINI, G.; SILVEIRA, A. Funções, atividades e responsabilidades da administração de compras: comparação entre empresas catarinenses e norte-americanas. In: ENCONTRO DA ASSOCIAÇÃO NACIONAL DE PÓS-GRADUAÇÃO E PESQUISA EM ADMINISTRAÇÃO, 28., 2004, Curitiba. Anais... Curitiba: ANPAD, 2004. CD-ROM.

RESENDE, P. T. V.; MENDONÇA, G. D.; ARAÚJO, B. B. Estratégias de formação de ambientes colaborativos com fornecedores no gerenciamento das cadeias de suprimento no Brasil. In: Encontro da ASSOCIAÇÃO NACIONAL DE PÓS-GRADUAÇÃO E PESQUISA EM ADMINISTRAÇÃo, 29., 2005, Brasília, DF. Anais... Brasília, DF: ANPAD, 2005. CD-ROM.

ROESCH, S. M. A. Projetos de estágio e de pesquisa em administração: guia para estágios, trabalhos de conclusão, dissertações e estudos de caso. São Paulo: Atlas, 1995.

SAATY, T. How to make a decision: the analytic hierarchy process. European Journal of Operational Research, Philadelphia, v. 48, p. 9-26, 1990.

SAATY, T. Método de análise hierárquica. São Paulo: McGraw-HillMakron, 1991. 
SLACK, N.; CHAMBERS, S.; JOHNSON, R. Administração da produção. São Paulo: Atlas, 1999.

WEBER, C. A.; CURRENT, J. R. A multiobjective approach to vendor selection. European Journal of Operational Research, Philadelphia, v. 68, p. 173-184, 1993.

YIN, R.K. Estudo de caso: planejamento e métodos. São Paulo:

Bookman, 2001.

Artigo recebido em: 21/12/2012

Aprovado em:18/06/2013 


\section{APÊNDICE A - Primeiro instrumento:}

A Bio-Manguinhos possui vocação científica e industrial para prevenir, identificar e tratar doenças por meio de vacinas, reativos para diagnóstico e biofármacos. Contudo, desenvolver um produto dessa magnitude pode levar, em diversos casos, mais de 20 anos, requerendo alto volume de recursos financeiros, recursos humanos capacitados e tecnologia disponível. Por ser uma instituição pública, a Bio-Manguinhos compartilha com o restante da máquina pública toda a dificuldade em obter recursos, os quais, quando obtidos, são em sua maioria insuficientes.

Diante desse cenário, a busca por parcerias externas tem se mostrado interessante, visto que o Brasil possui pouca capacidade de investimento em pesquisa e desenvolvimento de novos produtos e, consequentemente, de novas plataformas tecnológicas capazes de suportar a produção de novos produtos e atender à demanda da população do país.

Ao buscar parcerias, a Bio-Manguinhos pode se deparar com situações em que existam mais de um fornecedor para o mesmo produto, fazendo com que selecione um em detrimento de outro. $O$ presente estudo vem de encontro a essa questão, visando contribuir para a seleção desse fornecedor.

\section{Perguntas:}

1) $\mathrm{Na}$ busca por parcerias para a geração de um novo produto, quais os fatores/critérios mais importantes para selecionar um dentre vários fornecedores?

2) Dos critérios listados, quais os cinco mais importantes?

3) Qual a hierarquia desses critérios? Considere a ordem do mais importante para o menos importante. 


\section{APÊNDICE B - Segundo instrumento:}

\section{A MESMA INTRODUÇÃO DO ROTEIRO DE ENTREVISTA ANTERIOR.}

Foi feita uma entrevista com cada vice-diretor e identificado quais seriam os critérios relevantes para a seleção de um fornecedor.

\section{Perguntas:}

Diante dos critérios apontados pelos vice-diretores, atribua relações e compare-os par a par utilizando a tabela de nove níveis de Saaty.

Para realizar essa comparação par a par, primeiro responda qual dos dois critérios é o mais importante e depois atribua o grau de importância de acordo com a escala de nove níveis.

Foram apresentados, então, um quadro no formato da Tabela $02 \mathrm{e}$ o quadro com a Escala de Saaty. 